\title{
Conceptual Design of Future Undersea Unmanned Vehicle (UUV) System for Mine Disposal
}

\author{
Kwang sub Song, Senior Member, IEEE, and Peter C. Chu
}

\begin{abstract}
A conceptual design is proposed for an effective mine countermeasure (MCM) system, which consists of three unmanned underwater vehicles (UUVs) and 10-20 small charged deliverable vehicles. New underwater optical communication systems are introduced to improve onboard mine reconnaissance and decision making with the key technologies focused on system and communication efficiency, capability of data processing, and cost-effectiveness of MCM systems. The proposed UUV MCM system is cost-effective due to adapting disposable mine neutralization instruments, upgrading data process units, and configuring optical communication systems between heterogeneous underwater and surface vehicle units in operations. At the same time, efficient and reliable underwater optical and electromagnetic wave communication systems are also introduced and analyzed for future system applications.
\end{abstract}

Index Terms-Conceptual system design, mine disposal system, system effectiveness, unmanned underwater vehicle (UUV) technology.

\section{INTRODUCTION}

$\mathbf{T}$ HE SEA MINE, one of the most cost-effective naval weapons, represents a significant threat even to the most sophisticated warships. While originally equipped with a simple contact mechanism, it gradually became more advanced [1], [2], incorporating a range of smart detonators. A wide variety of mine types are deployed today, and many of them are highly sophisticated [3]-[5]. Although mines attack individual targets, their effects can be far-reaching at fleet and theater levels. In practical conditions, a naval force at sea might be obliged to modify its course of action due to the perceived or actual presence of mines. The disproportionate effect of a single mine strike might be enough to threaten mission accomplishment of combat forces. Some potential impacts of enemy mining operations include loss or delay in the arrival of carrier-based air power, amphibious assault forces, equipment, and supplies prepositioned afloat or ashore, and logistic support carried on either naval or supporting commercial vessels.

Manuscript received July 14, 2011; revised February 17, 2012 and April 20, 2012; accepted April 23, 2012. This work was supported jointly by the Office of Naval Research, under Grant N0001412WX20510, and by the Naval Oceanographic Office, under Grant N6230611PO00123P.

The authors are with the Department of Oceanography, Naval Postgraduate School, Monterey, CA 93943 USA (e-mail: kssong@nps.edu; pcchu@nps.edu).

Color versions of one or more of the figures in this paper are available online at http://ieeexplore.iee.org.

Digital Object Identifier 10.1109/JSYST.2012.2210592
So far, the mine countermeasure (MCM) missions have been executed by dedicated surface vessels and organic airborne operations with helicopter squadrons. With maneuvering helicopters, airborne mine neutralization system (AMNSYS), organic airborne and surface influence sweep, rapid airborne mine countermeasure system, and airborne laser mine detection system operations are executed for major naval littoral or expeditionary MCM and marine amphibious operations. These operations are only possible for secured sea lanes of communication or ships with very shallow water operation. Enough distance for standoffs and a wired communication and control connection are required for more clandestine and effective mine neutralization operations in mine disposal operations [6].

Military forces in the future will fight in conflicts ranging from major theater war to smaller scale contingencies. Naval forces will often be on the leading edge of such operations as they combine strategic mobility with maneuverability to significantly expand the battle space deep into the enemy territorial seas. Many tactical operations including special force operations, no matter big or small, should be carried out with time sensitiveness and clandestine operations [7].

The unmanned underwater vehicle (UUV) provides strategic and operational advantages to the Navy and security forces by reducing the cost and human risk significantly in the MCM operations, as well as by extending the reach of information, surveillance and reconnaissance. These UUV systems, which can be launched off the naval platform, offer significant protection against major threats including naval mines [8]. With the state-of-the-art technology developments [9], it is possible to perceive conceptual design ideas for future MCM UUV systems with safety, high effectiveness, and cost-effective systems.

In this paper, we design an MCM unit with three UUV systems executing clandestine MCM operations with formidable autonomy in the deep sea in enemy territory. With the powerful data processing capability, networked between UUVs and the mother ship through electrooptic and acoustic communications, and a new type of disposal scheme, the proposed MCM unit is linked into a network of unmanned asset and combat system elements. These systems provide a complete unmanned fleet fulfilling multiple operational requirements in mine disposal operations with least human operator interactions.

The status of underwater mine disposal systems is reviewed in Section II. A design of a prospective MCM system is depicted in Section III. A conceptual design for a future mine 
TABLE I

EXAMPLE OF DEDICATED MCMUUV SYSTEMS

\begin{tabular}{|l|c|c|c|c|c|c|}
\hline System & Dimension $(\mathrm{m})(\mathrm{l}, \mathrm{w}, \mathrm{h})$ & Weight $(\mathrm{kg})$ & Depth $(\mathrm{m})$ & Speed (CKTS) & Payload $(\mathrm{CKg})$ & Endurance $(\mathrm{h})$ \\
\hline $\begin{array}{l}\text { Remote multimission } \\
\text { vehicle }\end{array}$ & $(23.0,4.0,4.0)$ & & 200 & 15 & & 72 \\
\hline Sea Otter MKII & $(3.45,0.96,0.48)$ & 1000 & 600 & 5 & 160 & 24 \\
\hline Marlin & $(16,5,5)$ & 3500 & 1000 & 5 & 500 & 30 days \\
\hline Talisman & $(4.5,2.5,1.1)$ & 1800 & 300 & 5 & & 24 \\
\hline LMRS & $21 ”$ diameter & & 1500 & 15 & & 62 \\
\hline MRUUVS & Under development & & & & \\
\hline
\end{tabular}

disposal UUV system is given in Section IV. System measure of effectiveness is discussed in Section V. Underwater optical communication is presented in Section VI. Conclusions are given in Section VII.

\section{UNDERWATER Mine DisPOSAL SySTEM}

Surface ships and helicopter-based systems equipped with remotely operated vehicles (ROVs) are commonly used in MCM for mine detection, classification, and neutralization [10]. These remotely operated and teleported MCM ROV systems are controlled via hard wire or optical fiber links. While many of these vehicles have some automated functions, they do require human operators in the loop at least in a supervisory capacity [10].

With advances in technology, various mechanical platforms and instrumentations for ROVs are provided for mine identification and neutralization. Many ROV systems are available worldwide ranging from hand-held to tractor-trailer sized. The majority of ROVs, especially for MCM operations are built in a mid-range capability [11].

The U.S. Navy's AMNSYS has been developed using remotely controlled expendable vehicles identified as neutralizers, launched from an MH-53E airborne mine countermeasure helicopter [12]. While the neutralizer vehicle approaches toward the target, the targeted mines are monitored, identified by the on-board visual sensors, and destroyed by the shaped charge devices, which are integrated into the neutralizer.

Recently, UUVs have emerged as a major MCM platform for mine search, detection, classification, and neutralization. While designed to operate independently from continual human control, many of them have some auxiliary communication link used for the transmission of data, but not for direct commands and control. With no hard tether connections, a UUV can cover far greater operational fields than that of ROV, providing a much greater standoff capability from the manned platforms [12].

The major limitation of UUVs is, of course, limited independent operations for extended period of time. Data are often collected and stored on the vehicle. A significant time delay may occur before the data are available for processing and action by humans in the loop.

With the current state-of-the-art technologies, UUVs are already used in mine detection and classification, and several UUV systems are used in real MCM operations (Table I) with satisfactory performances [13]. Others are forthcoming in the near future with matured autonomy and performance capabilities.

\section{Future Mine Disposal UUV Systems}

The Navy's MCM doctrine has not been significantly changed since World War II. The future Navy may require significantly less available time to accomplish the MCM missions in the future network centric warfare [14]. Organic MCM forces must be closely integrated into and continuously provide information to the commander with status of hostile mine threats. This situation leads to the usage of a variety of autonomous platforms and sensors, which, in turn, makes the future doctrine noticeably different from today's doctrine. A new MCM doctrine will be developed, evaluated, and revised as the experiences, systems, and operations evolve. Its basic philosophy for the tomorrow's MCM is safe, effective, and clandestine operations with relation to the network-oriented future warfare [14].

In the future MCM operations, the decision-making software and combat information display systems will be cooperated with data collected and communicated from extensive multisourced agents. The command, control, communications, computers, and intelligence architecture will be networked to ensure the existence of communication paths between platform and detachment despite uncertain point-to-point links. Future MCM operations with autonomous vehicle systems will be more effective and safer due to all these doctrinal evolvements, technology developments, and advanced hardware with up to date intelligent software [15].

Exact path planning, smart navigation, and mine neutralization depend on the capacity and accuracy of navigation systems, which must avoid mines for the safe transit of ships and must be sufficiently precise to decide the reacquisition of the target. A simultaneous localization and mapping system (SLAM) and real-time autonomous identification of underwater environment can be used to accurate target recognition and MCM operations.

The coordinated MCM mission management system optimizes available sensors and subsystems, regardless of the host platform, to ensure the most effective measure when and where it is mostly needed. Fundamentals to the MCM operational concept are to locate mine fields, identify no-mine areas accurately, and clear mines efficiently as soon as possible [16]. This will require detection of mines or enemy mine laying activity anywhere in a large area, such as thousands of square kilometers. 


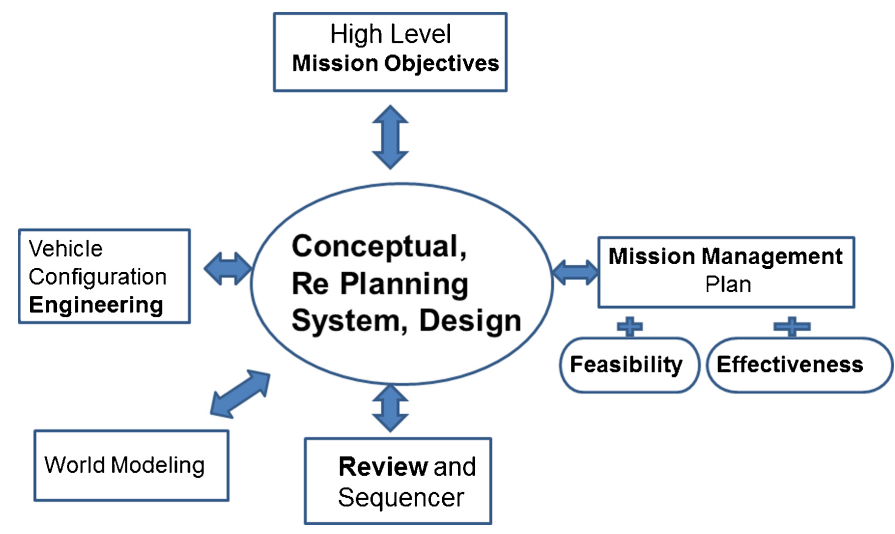

Fig. 1. Conceptual design process.

Payloads for MCM vehicles generally consist of a maneuvering system, neutralization charges for elimination of bottom mines, or cable cutters for moored mines. Auxiliary technology equipment as a part of payload is also playing an important role in enhancing the computer graphic and visualization capabilities. The payloads contribute greatly to sensor integration, simulation, decision making, and training. The commander must have the capability to avoid mines or achieve the assured destruction or neutralization of a mine threat within the absolutely minimum time. The mine sweeping system must be effective against buried, bottom, moored, or floating mines from the deep water to the anti-invasion zone on the beach. There are several state-of-the-art weapon systems to dispose of the mines effectively and economically, such as laser guns, acquire guns, and small charge delivery devices.

\section{CONCEPTUal Design For Future Mine DISPOSAL UUV SYSTEM}

The conceptual design for the futuristic MCM UUV system is developed with operational and technical prospects based on investigation of a wide spectrum of current MCM operations. For complex systems such as MCM UUV units, there is no clear boundary between requirement and design. In general, a high-level design on the UUV systems for MCM operations is developed from an abstract specification to detailed specification. The concept of system configuration is proposed in response to some perceived possible problems in the mine warfare (MIW) and operational concept formulation.

Fig. 1 shows the conceptual design process for general systems. The key system design concepts from analyzing missions of a future MCM UUV system are structural configurations and effectiveness of system operations [17]. An objective of system design is to build cost-effective and efficient MCM UUV systems, which can operate in permissive littoral and ashore environments with water depth of 10-90 m, including harbors and shipping channels. These systems will utilize known tactical and target information, which is preacquired by previous MCM reconnaissance troops and assets with about $75 \mathrm{~h}$ of endurance and over $160 \mathrm{~km}$ of operational range.

Generally, in a conceptual vehicle design, two sets of input parameters are needed: mission description and vehicle configuration options [18]. A vehicle mission is divided into user-prescribed discrete segments. Each segment is defined by its unique parameters, which include vehicle conditions, hotel power, payload conditions, and environmental conditions. The vehicle configuration options are generally obtained from vehicle's top level requirements and the concept of operations (CONOPS). Collaboration between the highly object-oriented autonomous vehicle configurations and the low-cost mine neutralization UUV is viewed as an essential element of reliable mine neutralization operations [18]. Guidance, navigation, and control of UUV instrument configuration are implemented automatically to derive an optimal detailed mission path plan by processing navigation sensors, such as sonar imagery, position, range, bearing, and underwater database information [19].

\section{A. CONOPS}

Main concepts of MCM operations using UUV systems are to reduce threats for the naval fleet through employing a robust, highly autonomous vehicle unit, which is capable of engagement and execution of mine sweeping or neutralization procedure. The neutralization procedure entails either moving the mine out of the original place or precise delivery of the charged device to blast previously localized mines, in volume, drift, floating, and bottom mines in the deep and shallow water zones [20], [21]. The proposed MCM UUV system unit is over the horizon launching system which has a master UUV and two expandable slave UUVs at the two sides of the master UUV. The large master UUV has a main mission control unit and formed charge that can reach and explode designated mines. The two slave UUVs have various mine detection and search sensor systems, which can improve mine detection or identification and provide cooperative maneuvering using stereoscopic viewing. This system greatly enhances the maneuvering capability especially in the case of no communication such as in accident. The two slave UUVs provide maneuvering of the master UUV using stereoscopic views.

Before actual mine disposal activities, the control unit of the master UUV requests confirmation of mine identification to the mother ship via acoustic and radio frequency (RF) communication links. Responding to the reply, the master UUV deploys a charged payload, which is a small and fast guided device with high-power formed charge with proxy sense running a straight course to the identified mine targets. The MCM UUV unit will have, overall, $75 \mathrm{~h}$ of endurance at 3 knots maneuvering and $160 \mathrm{~km}$ of operational range.

In the envisioned CONOPS, an MCM UUV unit uses its high-capacity communication links to receive available targeted mine information from the MCM operation center at the mother ship. The vehicle initiates an adaptive engagement plan autonomously along its trajectory with available information from own navigation sensors. It navigates accurately to the designated mine target in compensating winds, waves, and currents along the disposal range. All the way to the designated mine position, the launched disposal device identifies the targets from the sonar image. After neutralizing the designated mine, the UUV unit performs a neutralization damage assessment and reports that the mission has been accomplished. 


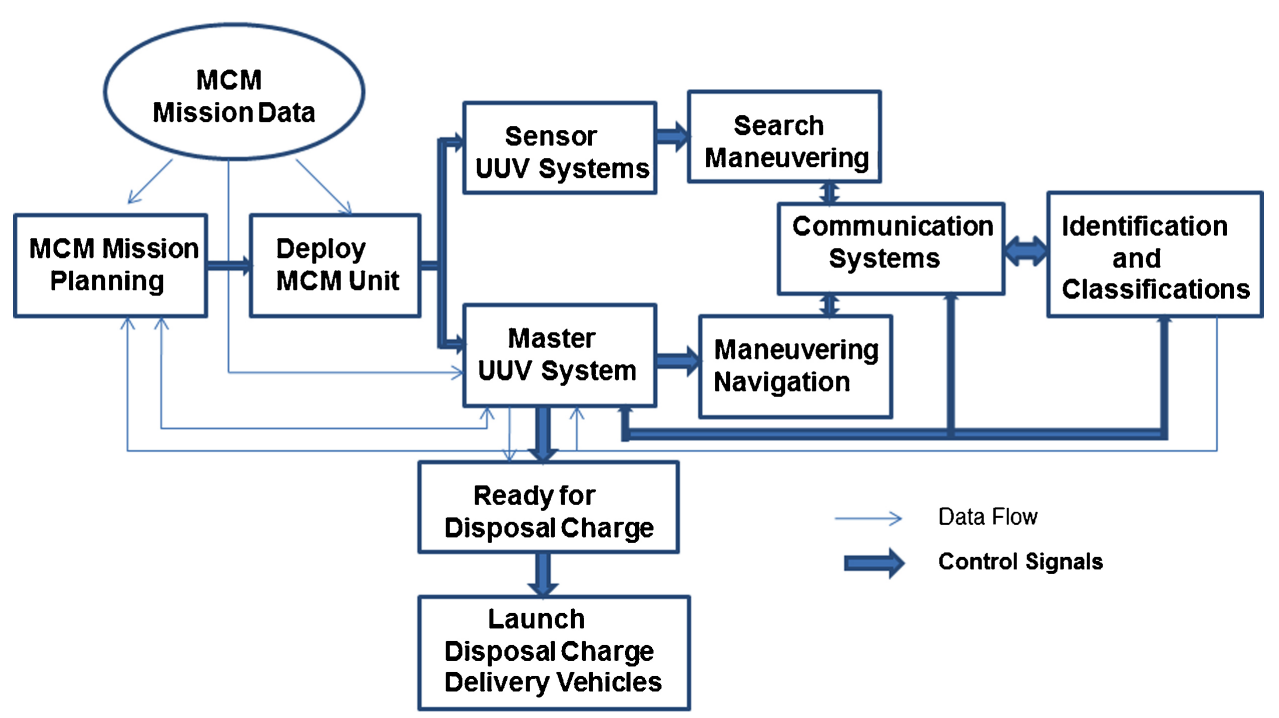

Fig. 2. Operations of MDUSU.

\section{B. Structural Configuration of a 3-UUV Mine Disposal Unit}

The mission description of MCM fleet operation is divided into five segments: launch, transit, execution of mission, return transit, and recovery. Each of them is defined by key mission and environmental parameters, such as range, speed, sea current, obstacles, and underwater terrain. The description of vehicle hardware configurations is parameterized with typical undersea vehicle's fineness ratio: values of three, five and seven, indicating the ratio of length to diameter. Large variations in mission distance and ground speed result in nonpragmatic scenarios. The options for vehicle hardware configuration dictate the set of vehicle design variations, which are evaluated by the design requirements. Important options are the fineness ratio and block coefficient, which dictate the basic packaging and sizing of all other vehicle subsystems. These kinds of shape and hard stuffs would be characterized later in a detailed actual design phase. In the conceptual design phase, several key performance functional characteristics of major MCM operations are investigated.

\section{Configuration of the Master UUV System}

The proposed mine disposal UUV system unit (MDUSU) demonstrates a number of capabilities, supporting autonomous mine detection, identification, and intervention using system autonomy, communication endurance, and small charge delivery vehicles (SCDV). Advanced technologies for these capabilities include situational reactive intelligent mission control suits, smart sensor systems, dynamic intelligent data classification processes, precise inertial undersea navigation, and compact vehicle autonomous management subsystems [22].

Improvement of vehicle functionality and mission effectiveness of MCM UUV system unit are the primary objectives of this research. The MCM UUV unit provides autonomy of vehicle systems through incorporation with a platform-independent autonomous controller that supports high degree of autonomy, highly precise low-power navigation, and machine vision in support of automatic classification [23].

1) Mission Management Unit: Mission control architectures of MDUSU embrace various degrees of perceptions, intelligent control, and management to define sense-plan-act or sense-react behaviors. The MDUSU architecture and its relationships to the executors and the data or signal processing are shown in Fig. 2. Functional limitations of vehicle sensor systems imposed by the combat environment require alternative rates of vehicle control, which defined mission goals to be factored in the control system appropriately. A common approach to mission implementation is to develop functions that are grouped and sequenced to perform overall tasks.

These approaches can be grouped as task-oriented control architectures with tasks ranging from simple to complex. Application of the defined tasks to accomplish a complex mobile robot behavior becomes a function of sequencing. Much research has been completed in architectures with required different degrees of sequencing. These architectures range from state-defined multilayered integration to near-chaotic independent function execution approaches. The emerging paradigm with a three-level architecture is embodied in a number of UUV mission management algorithms. This system provides the planning or specification of operations at the abstract level, a level of functionality that facilitates the abstraction, and a level that provides the actual functionality [23].

MDUSU embraces this hybrid mission control and vehicle management architecture. It refines a traditional perceptionaction loop, allows signal processing for a low-level sensor, and extracts features to assist mission planner and control system. The management system of MDUSU focuses on object classification and dynamic repositioning, which optimizes the aspect relative to the designated mine target. Obstacle avoidance acquires relatively sparse sensor data in the dynamic construction of world models. Combining the perception or classification with dynamical position sensors via a highly 
TABLE II

COMPARISON OF DIFFERENT TECHNOLOGIES FOR UNDERWATER COMMUNICATION

\begin{tabular}{|l|c|c|c|}
\hline & Acoustic Communications & Electromagnetic Communications & Optical Communications \\
\hline Nominal speed $(\mathrm{m} / \mathrm{s})$ & 1500 & Light-speed & Light-speed \\
\hline Power loss & $0.1 \mathrm{~dB} / \mathrm{m} / \mathrm{Hz}$ & $28 \mathrm{~dB} / 1 \mathrm{~km} / 100 \mathrm{MHz}$ & Turbidity \\
\hline Bandwidth & $\mathrm{kHz}$ & $\mathrm{MHz}$ & $10-150 \mathrm{MHz}$ \\
\hline Frequency band & $\mathrm{kHz}$ & $\mathrm{MHz}$ & $0.1 \mathrm{~m}$ \\
\hline Antenna size & $0.1 \mathrm{~m}$ & $0.5 \mathrm{~m}$ & $10-100 \mathrm{~m}$ \\
\hline Effective range & $\mathrm{km}$ & $10 \mathrm{~m}$ & New \\
\hline Technology & Mature & New & \\
\hline
\end{tabular}

maneuverable platform, MDUSU has the capability to perceive the object of interest from multiple perspectives that increase the probability of classification for the mine targets. A key concept in MDUSU data fusions includes the employment of heuristic knowledge, which incorporates constraint knowledge associated with target characteristics and vehicle capabilities. It provides a basis for interaction with the object of interest and dynamic perceptions for active sensor management and vehicle path planning.

2) Mapping and Navigation Unit: The system's capability of precise navigation and large sensor data collection is critical in ensuring operations and achieving system objectives. To resolve the vehicle position at the submeter level, a compact low-power solid state inertial measurement unit (IMU) is incorporated. This unit measures the change of 3-D velocity and angular velocity, and temperature as well to correct thermally induced drift. The IMU is augmented by a compact Doppler sonar using the Kalman filter or other filtering techniques. Navigational accuracy of MCM UUV unit may be further enhanced through the integration of long-baseline or ultrashort baseline acoustic navigation information [24]. Precision navigation compass and clinometers provide heading information and navigation frame correction data.

SLAM techniques as navigational tools are adapted for reconfirmation of designated mine localizations and autonomous navigation with obstacle avoidance in a safe margin. All the information from sensors is filtered, processed, and distributed for navigation, SLAM, and mine neutralization procedure [25]. With updated environmental 3-D map and obstacle information, MDUSU can be guided and controlled in an optimal path to the targets with accuracy.

3) Data Processing and Mine Classification Unit: An algorithmic approach in data processing is used with machine perceptions, recognitions of acquired data, and feature extraction via real-time image processing. It will support automatic classification of mines and other ordnances, as well as intelligence navigations using data from navigation sensors [26]. The image processing techniques, which have been adapted from video image and sensor signal processing, focus on classification of mines by recovery of explicit featurebased descriptions of manmade objects [27]. All the data from traditional navy database library systems on MIW, MCM, and tactical oceanography are also installed in main processing unit of MDUSU and fed into the identification and classification processors [28].

4) SCDV Unit: When the matser UUV of MDUSU reaches the safe standoff range from the mine field after relocalization and confirmation of predesignated mine or mine group, around 20 SCDV units are launched to the individual or grouped mine targets. Stand-off distances from the mine field are determined from the safe distances of mine explosion and tactical considerations in underwater environments [29]. The SCDV has high explosives sufficient for mine disposal in the vicinity of targeted mine appropriately. SCDV is a small straight run torpedo system with batteries powered, $200 \mathrm{~m}$ range, 35 knots speed, and high formed charge triggered from vicinity/timer sensor.

5) Communication Unit: Reacquisition and relocalization of predesignated mine or mine fields involve huge amount of data from various sensor systems. The Navy database packages for static mine identification and classification are also available from onboard MDUSU data storage. Data for reconstructing three and 2-D models are also significantly large. It is very difficult to transfer through current acoustic carrier in underwater environments [30]. Some other information from distance and directional angle of illumination of light source give some incentive weight on reconstruction of mine models.

Identification and reconfirmation of MLOs from real mine targets are critical factors for mine disposal operations. Other kinds of optimized communication carriers are urgently needed during data processing and transmitting in the main control center of MDSUS. They deal with high-quality mine detection sensor data from remote area, but lack the computational capability of the existing data processing systems [31], [32]. Applications of RF and laser optic technology are considered as potential alternative methods of effective underwater communication systems. Table II shows a possible candidate (laser optics) for future underwater communication systems, which have high capacity in data processing and transmitting with ranges around $100 \mathrm{~m}$.

\section{Slave UUV System}

With high-quality wireless laser communication links or fiber optic wire link, a slave UUV system could have high fidelity detection sensors, such as synthetic aperture sonar, sidescan sonar system (SSS), light detection and ranging (LIDAR), and vintage channel (VC). All the data collected from the sensors onboard slave UUV are transferred to the signal processing unit of the master UUV as soon as possible, where identification and classification of mine and MLOs are processed and redesignated as targets of disposal operation.

Two slave UUV operations benefit the cooperative navigation which help MCM unit navigational sensor, and all the sensors on the slave UUV provide stereoscopic signal to the 
main processing center for identifying mine and mine-like objects. The slave UUV systems are attached each side of the master UUV where they are performing as the navigation sensor, until it is moving to the targeted mine field. In the mine field, where the actual mine disposal operation is supposed to be executed, the slave UUVs are separated from the master UUV and maneuvering $100 \mathrm{~m}$ ahead of master UUV. They start to search mines with forward-looking sonar at $200 \mathrm{~m}$ forward, SSS at $100 \mathrm{~m}$ ahead, LIDAR at $50 \mathrm{~m}$, and VC within $10 \mathrm{~m}$ ahead of prospective mine targets, and also collect the navigation data for obstacle avoidance. All the data collected in the slave UUVs are transferred to the master UUV in real time for processing. After reconfirmation of mines is completed, the slave UUVs return and dock to the side of the master UUV as a navigation sensor for mine disposal operations.

\section{System MEASURE OF EFFECTIVENESS}

\section{A. System Evaluation Model}

With state-of-the-art technologies in sensing, communication, and navigation, the future MCM operations with autonomous mission management systems are likely to use multiple heterogeneous UUVs working together to improve effectiveness of overall MCM operations [33]. In the final phase of system design, either conceptual or actual, justification studies for the proposed design should be carried out with functional and cost-effectiveness evaluations. It is required to change, modify, or compromise original design configurations, if there are better alternatives or deficiencies for the original proposed design concepts, system's structural configurations, instrumentation, and operational systems [34]. Here, analytical frameworks are developed to evaluate the proposed MCM disposal UUV unit based partially on the current U.S. naval underwater ship design procedure.

The parameters of mission effectiveness are organized into hierarchy and weighted utility functions. The evaluation models provide means to relate the effectiveness matrices to the system-level performance parameters. These individual capabilities can be stated in terms of vehicle subcomponents, such as sensors, data storage, processing unit, communication systems, navigation instrumentations, and disposal payload items [34].

The general approach to the measure of effectiveness (MOE) is to make higher level models as generic as possible, and to increase detail and resolution with each progression into lower level models. This is accomplished by developing separate model subcomponents and linking them together to form an overall system model [35]. The results from the effectiveness and risk management models lead to the MOE and comparison between the MOE and cost leads to the decision making, or modifying system model.

\section{B. System Effectiveness Analysis}

For an entire MCM evaluation framework, the specific operational requirements on the MOE for MCM UUVs lead to the following important items [36]: 1) near real-time communication with information and data links between unit and host platform of the UUV systems in the future C4ISR environment; 2) system autonomy and mission achievement; 3) covertness of UUV systems measured and incorporated into the MOE; 4) requirements of logistics support for deployment and recovery; 5) requirement of human supervision and oversight as least safety protection measure; 6) risk management; and 7) cost factor for UUV.

For the UUV systems, especially for multiple vehicle systems, covertness and communication abilities depend significantly on the position and operational configuration of the disposal system unit. Thus, for the UUV disposal system unit, the mission time, mission achievement, autonomy, communication, covertness, risk management, and cost-effectiveness are the highest level of the proposed MOE hierarchy [36].

1) Mission Achievement Efficiency: Success of neutralization is the main object of the MCM operations and this MOE represents the estimated probability of search or classification of mine and mission accomplishment for mine clearance. Mine reconnaissance and clearance are the two basic MCM missions. The major objectives of mine reconnaissance are accurate search, localization, and regain of designated mine in the contacts. Search level refers to cumulative probability of mine detection and relocalization, classification, and identification within specified MCM operational area. The search and identification of proposed system are validated through sensor systems, communication efficiency and data processing capability of main control unit.

Degree of autonomy for the vehicle operations is regarding smartness of main operating computer architectures governing guidance/navigation/control of vehicle, mission management and obstacle avoidance/optimal path planning that are required during the MCM mission operations. The nature of the MOE is well defined by numeric symbols on the level of autonomy table, which is published by the U.S. Department of Defense, and shows autonomous system's capability of processing unit, level of machine intelligence, and database capacity for data resources applied for decision making on the specific missions [37].

The new state-of-the-art communication devices use the laser optic rays and RF carriers rather than the conventional underwater acoustic wave medium. The laser optical and RF devices have the capability for data transfer with high speed and security, but a moderate communication range in the underwater environments [38]. Communication systems related to the mission operations are data communication links where tactical maneuvering information on the MCM missions is exchanged. Each division on communication links is evaluated through communication quality of data, security and interoperability.

2) Risk Management: The purpose of the risk management is to find possible system deficiencies during operations and to integrate quantitative measures with respect to risks. Three types of risks associated with mine disposal UUV unit are: 1) technological factors; 2) overall cost of system operations; and 3) scheduled sequences of maneuvering [36]. The technological factors include propulsion, computer systems, communication systems, and weapon systems. These risks with 
mission executions are managed appropriate back-up mission management systems added to the main system operational nodes [36].

3) Cost Analysis: Since this research is a conceptual design for the future systems, the life cycle cost (LCC) and total ownership cost (TOC) [39] are used for the analysis. LCC is the direct total cost to the government of acquisition and ownership of a system over its useful life. It consists of four parts: development, acquisition, operations or support, and disposal costs. Among the four types of costs, the operations or support cost is generally the highest, followed by acquisition (or investment) cost, development cost, and then the disposal cost.

TOC is basically the LCC with indirect components such as the cost of manning. In the ship synthesis model, the labor cost and the material cost are calculated separately. Regarding the TOC of the MCM disposal UUV unit, this proposed MCM UUV system unit is economic, intelligence system of systems, reusable as long as it would be operational. The only disposable expenses would be SCDV units, which is both simple system and inexpensive, compared to the other major mine disposal systems.

\section{FEASIBILITY STUDY ON UNDERWATER OPTICAL COMMUNICATIONS}

\section{A. Importance of Underwater Communication}

Executions of MCM operations must be carried out in a short period of time before enemy forces to respond. Therefore, planning of MCM operations needs to be systematic based on exact combat information over large areas of prospective operations and evaluation for the nature of the operations. Large volume of information is collected from surveillance and reconnaissance on the mine fields, and they should be formatted for quick dissemination to the MCM control center and disposal units respectively.

With advances in technology, UUV can maneuver over a large area of operations, collect information for a large mine field, and transfer acquired information to the MCM operation control center promptly. One of the most important issues in MCM operations is underwater technology for high effectiveness in data and information communicating and processing [40]. To assure success of MCM operations, the commander of the MCM units should understand the impact of situational awareness about actual environment and current available combat information for the mine fields. The effectiveness of MCM operations depends largely upon underwater environment, accurate combat information, data processing capability, weapon systems, and communication networks among MCM operational units [41].

Due to special characteristic features in the underwater environment, acoustic waves are used as the primary carrier for underwater wireless communication systems due to relatively low absorption and transmission losses. Up to date and extending to the near future, acoustic waves will remain the major carrier of wireless communication for the UUV systems. For acoustic wave carriers, the key challenges are identified in communication quality and networking systems, such as time delay, data rate, and noise characteristics [42].

With those characteristics of underwater acoustic communications, future MCM operations will face several difficulties on effective and safe MCM operations. We plan to apply new technologies for future MCM operations with RF and optical underwater communication links, which can provide higher speed as well as better quality of operations. These futuristic underwater communication technologies are at their development phase, but have already shown major technological breakthrough on underwater communication systems and applications.

\section{B. Required Information on MCM Operation}

In the MCM operations, correct mine recognition with a high probability and exact mine classifications lead to success of MCM missions. The first level of recognition is usually considered perception of mines. If the call for initial mine recognition is false, then much valuable time is wasted in investigating possible targets. Correct identification of the target ensures that overall MCM operational sequences are on the correct track of actions.

For most cases, classification of a man-made object is enough for the next step, but this kind of classification is reliable if and only if identification is possible. Cameras with high resolution and fast shutter speed are, therefore, desirable for search and reconnaissance of mine fields. Higher resolution can obviously yield a better target definition, while faster shutter speed would produce more multiple looks at the target. New data processing techniques would incorporate multiple looks and statics of the surface to extract better information about the imaged objects. Under current technology, once data are communicated and collected appropriately, powerful data processing unit at the main control center has the high capability to process, recognize, and decide object identifications within a minimal processing time [43].

Location of a specific mine and relocalization of mine fields are very important for UUV maneuvering in the MCM operations. Identifying the precise location of mines gives the navy commanders the flexibility to choose the best course of future action of operations. Even when the mine threat is widely dispersed, avoidance can be a viable action. If instead, choosing to destroy the threat, time becomes an important factor too, and again, precise location will minimize the wasted time. The accuracy around one meter is needed for truly effective operations [44].

\section{Development of Underwater Optical Communications}

In modern MCM operations, time delay and slow data transfer between mine searching sensor system and data processing unit at the MCM control center are great barriers for MCM operations. To overcome such operational weakness and difficulties, the blue laser optical sensor and communication systems are prospective options for the underwater information networks [45]. Use of optical rays for underwater communication has a big advantage in data transfer rate, which can potentially exceed $1 \mathrm{~Gb} / \mathrm{s}$. However, it has several 
disadvantages. First, the optical signals are rapidly absorbed in the water. Second, the optical scattering caused by suspending particles and planktons is significant. Third, high level of ambient light in the upper part of the water column is an adverse effect for using optical communication. Fourth, optical scattering is the topic more pertinent to using optical waves for communication [45].

Water quality plays a key role in determining if optical waves can be used for underwater communication. As a result, the applicability of optical communication depends heavily on the environments. Similarly to the acoustic and electromagnetic waves, the underwater optical communication systems work in the environmentally limited region [44]. Recent interests in underwater sensor networks and sea floor observatories have greatly stimulated the interest in short-range highrate optical communication [46]. So far, several good commercial optical modems are available specifically for underwater laser communications within $50 \mathrm{~m}$ range [47]. For example, SA Photonics is developing Neptune, a high-bandwidth, lowpower underwater communications system that is small and lightweight. Neptune can be used on submarines, ships, UUVs, and fixed undersea data nodes with the communication capability at data rate up to $300 \mathrm{Mb} / \mathrm{s}$ over the $50 \mathrm{~m}$ range. This system can automatically adjust data rate, modulation format, and laser wavelength based on water quality with optimal transmission and minimal power consumption. Woods Hole Oceanographic Institution has developed an undersea optical communications system, called the "virtual revolution in high-speed undersea data collection and transmission" [43], to provide near-instant data transfer and real-time video from untethered ROVs, UUVs, and seafloor data-collection or transmission sites. It is also used in conjunction with acoustic communications, which would take over once the vehicles moved out of the optical range. In any case so far, its designers have achieved data rates of 10 to $20 \mathrm{MB} / \mathrm{s}$, through $100 \mathrm{~m}$ of water [47].

\section{CONCLUSION}

In this paper, the current MCM systems and their operations in mine fields were investigated for possible technological improvements in future mine neutralization. Key technologies required for the future MCM systems were system efficiency, capability of fast data processing, communication efficiency, and cost-effectiveness.

Configuration of 3-UUV system unit has an effective conceptual system design with 10-20 small charge deliverable vehicles. New underwater optical communication systems were suggested to improve mine reconnaissance and decision making procedures in efficient operations. Cost-effectiveness of the MCM system operations was studied through analysis on conceptual design configurations with disposable mine neutralization instruments, upgraded data processing units, and configuration of optical communication system between heterogeneous underwater and surface vehicle unit. Fine and reliable underwater optical communication systems will emerge in the very near future, as they are being actively researched with sufficient government support.

\section{REFERENCES}

[1] P. C. Chu, "Mine impact burial prediction from one to three dimensions," ASME Appl. Mech. Rev., vol. 62, pp. 1-25, 2009.

[2] P. C. Chu and C. W. Fan, "Probability density-function of underwater bomb trajectory deviation due to stochastic ocean surface slope," ASME J. Dyn. Syst. Meas. Cont., vol. 133, no. 031002, p. 13, 2011.

[3] P. C. Chu, J. M. Bushnell, C. W. Fan, and K. P. Watson, "Modeling of underwater bomb trajectory for mine clearance," J. Defense Model Simul., vol. 8, no. 1, pp. 25-36, 2011.

[4] P. C. Chu and C. W. Fan, "Mine impact burial model (IMPACT35) verification and improvement using sediment bearing factor method," IEEE J. Oceanic Eng, vol. 32, no. 1, pp. 34-48, Jan. 2007.

[5] Committee for Mine Warfare Assessment National Studies Board, National Research Council, "Naval mine warfare: Operational and technical challenges for Naval Forces," Committee Rep., The National Academic Press, Washington D.C., 2001.

[6] E. M. Sanders, "Amphibious operations in a mine environment," M.S. thesis, Maxwell Air Force Base, Montgomery, AL, Apr. 2000.

[7] C. J. Hyland, "Improving mine countermeasures mission performance with multidimensional tactical analysis," in Pillar V Emergent Technology Rep., Applications of Technology to Demining, Part II Naval Mine Countermeasure. Society for Counter Ordnance Technology, Monterey, CA, Jul. 2005.

[8] Office of the Assistant Secretary of the Navy, "Unmanned vehicles (UV) in mine countermeasures," Naval Research Advisory Committee Rep. NRAC 2000-3, Office of the Assistant Secretary of the Navy, Washington D.C., Nov. 2000.

[9] U.S. Navy Program Executive Office, "Littoral and mine warfare, U.S Navy, 21st Century U.S. Navy mine warfare," Dept. Rep., Program Executive Office, Littoral and Mine Warfare, Expeditionary Warfare Directorate, U.S. Navy, 2009.

[10] S. Satiel, T. Balch, and N. Erdogan, "Naval mine countermeasure missions," IEEE Robot. Autom. Meg., vol. 15, no. 1, pp. 45-52, Mar. 2008.

[11] B. Almquist, "Standoff systems and technologies for the near shore mine countermeasures (MCM)," in Proc. 5th Int. Symp. Technol. Mine Problem, Apr. 2002, pp. 1-8.

[12] A. Nativi, "UUV development accelerates," Aviation Week's Defense Technol. Int., vol. 113, no. 9, pp. 21-29, Sep. 2010.

[13] B. Evans, G. Davies, V. Myers, A. Bellettini, M. Pinto, and P. Munk, "Implementation of autonomous mission control for mine rrconossaince AUVs," NATO Rep. RTO-MP-AVT-146, 2007.

[14] B. Fletcher, "Worldwide undersea MCM vehicle technologies," Space and Naval Warfare System Center, San Diego, CA, Rep. MS-11, Mar. 2000.

[15] A. Mangolds, "The Lemmings/BUGS system," DARPA Phase II SBIR Rep. DAAH01-94-R047, 1994.

[16] G. M. Trimble, "Autonomous operation of the explosive ordnance disposal robotic work package using the CETUS unmetered underwater vehicle," in Proc. Autonomous Underwater Vehicle Technol. Symp., Jun. 1996, pp. 21-27.

[17] MATE Material, "UUV design flow chart," Univ. Victoria, Victoria, BC, Canada, MATE Tech. Rep. 2008, 2000.

[18] K. S. Song, "A conceptual design study for UCAV in application with naval operations," ROK Naval Research Lab Project Rep. NA-00-23, Chinhae, Korea, Dec. 2000.

[19] S. J. Osmundson and V. T. Huynh, "A systems engineering methodology for analyzing systems of systems," Dept. Inform. Sci. Syst. Eng., NPS, Monterey, CA, Dept. Internal Rep. ISSE-06, Jun. 2006.

[20] C. P. Nicholas, "Buried target image quality," in Applications of Technology to Demining, Part II Naval Mine Countermeasure. Society for Counter Ordnance Technology, Monterey, CA, Jul. 2005, pp. 203-207.

[21] M. J. Green, "Establishing system measures of effectiveness," in Proc. AIAA 2nd Biennial Forum Weapon Syst. Effectiveness, Mar. 2001, pp. $1-5$

[22] B. W. Song, Q. F. Zhu, and Z. Y. Liu, "Research on multiobjective optimization design of the UUV Ssape based on numerical based simulation," in Proc. ICSI, ILNCS 6145. 2010, pp. 628-635.

[23] B. T. Curtin, M. D. Crimmins, J. Curcio, M. Benjamin, and C. Rope, "Autonomous underwater vehicle: Trends and transforms," Marine Technol. Soc. J., vol. 39, no. 3, pp. 65-75, 2005.

[24] I. Woodrow, C. Purry, A. Mawby, and J. Goodwin, "Autonomous AUV mission planning and replanning toward true autonomy," Syst. Eng. Assessment, Ltd., Beckington Castle, U.K., Internet Rep. 2010-15, 2010 
[25] K. S. Song, "Trajectory smoothing of the AERIES AUV maneuvering in Monterey bay," Lab. Rep. NPS-ASL 07-30, NPS AUV, Monterey, CA, 2007.

[26] T. Bailey and H. Durrant-Whyte, "Simultaneous localization and mapping (SLAN): Part II, tutorial," IEEE Robot. Autom. Mag., vol. 13, no. 3, pp. 108-117, Sep. 2006.

[27] K. S. Song, "Application of navigational sensor data fusion technique to mine disposal vehicle (MDV) systems," ROK Naval Res. Lab Project Rep. NA-00-30, Chinhae, Korea, Dec. 2000.

[28] V. Sequeira and G. M. Joao, "3-D environment modeling using laser range sensing," Robot. Autonomous Syst., vol. 16, no. 1, pp. 81-91, 1995.

[29] U.S. Navy, "Mine warfare readiness and effectiveness measuring (MIREM),” Dept. Navy, Washington D.C., Operation Manual, Jun. 2005.

[30] F. Florin, F. Fohanno, I. Quidu, and J. P. Malkasse, "Synthetic aperture and 3-D imaging for mine hunting sonar," Thales Cooperation, Route de Santa Anne du Portzic, Brest Codex, France, Thales Underwater Syst. Rep. Hal-00504862, 2004.

[31] C. W. Cox, "A one Mbps underwater communication system using a $45 \mathrm{~nm}$ laser diode and photomultiplier tube," M.S. thesis, Dept. Elect. Eng., North Carolina State University, Raleigh, 2007.

[32] M. R. Wall, "Underwater laser applications," Opt. Technol., vol. 1, no. 3, pp. 130-139, May 1969.

[33] K. R. Bullock, "Theory of effectiveness measurement," Ph.D. dissertation, Air Force Instit. Technol., WPAFB, OH, ProQuest Dissertations and Theses Database, ADA No. 456717, pp. 1-234, Sep. 2006.

[34] C. Brown and P. R. Clark, "Using novel conceptual design utility to evaluate a long range, large payload UUV," in Proc. MTS/IEEE OCEANS, Sep. 2010, pp. 1-10.

[35] E. D. Harris and W. D. Shepherd, "A structured approach to the articulation of future mine countermeasure concepts," in Proc. Naval Surface Warfare Symp. Paper, Mar. 2000.

[36] W. G. Pollitt, "Mine countermeasure requirements to support future operational maneuver," Johns Hopkins APL Tech. Dig., vol. 21, no. 2 , pp. 280-287, 2000.

[37] H. A. Levis, "Measuring the effectiveness of C4I architectures," George Mason Univ., Fairfax, VA, C3 Architectures Lab. C3I Center Rep. GMU/C31-186-P, May 1997.

[38] B. Cochenour, L. Mullen, and A. Laux, "Spatial and temporal dispersion in high bandwidth underwater laser communication links," in Proc. IEEE Military Commun. Conf., 2008, pp. 1-7.

[39] M. Manazir, "Navy aviation: Building the future fleet," N4B Navy Readiness Overview Brief, NDIA Defense Forum Presentation, San Diego, CA, Feb. 2010.

[40] A. Weidemann, "Applications of NRL's littoral optical environment (LOE) program to MCM," in Applications of Technology to Demining, Part II Naval Mine Countermeasure, The Society for Counter Ordnance Technology, Monterey, CA, Jul. 2005, pp. 341-346.

[41] WFS, "Pioneering research into underwater RF technology," WFS Internal Rep. WFS 2010-4 Combo, WFS Subsea Inc., Livingston, U.K., 2007.

[42] M. Stojanovic, "Underwater wireless communications: Current achievements and research challenges," IEEE Oceanic Eng. Soc. Newsletter, Nov. 2006, pp. 1-6.
[43] Y. Z. Liu and X. H. Ge, "Underwater laser sensor networks: A new approach for broadband," in Proc. WSEAS Int. Conf. Telecommun. Informations, May 2006, pp. 421-425.

[44] C. W. Cox, A. J. Simpson, P. C. Domizioli, F. J. Muth, and L. B. Hughes, "An underwater optical communication system implementing Reed Solomon channel coding," in Proc. IEEE Conf. OCEANS, May 2008, pp. 1-6.

[45] E. Farr, "Optical system could revolutionize underwater communications," in Proc. Ocean Sci. Meet., Feb. 2010, pp. 1-5.

[46] AZO Optics, "New optical communications system enables high speed undersea communications," AZO Optics Rep. 2010-2, Warrie, Australia, Feb. 2010

[47] M. S. Chen and S. Y. Zhou, "The implementation of PPM in underwater laser communication system," in Proc. Int. Conf. Commun. Circuits Syst., Jun. 2006, pp. 1901-1903.

[48] P. C. Chu and C. W. Fan, "Prediction of falling cylinder through airwater-sediment columns," ASME J. Appl. Mech., vol. 73, no. 2, pp. 300-314, 2006

[49] P. C. Chu and C. W. Fan, "Pseudo-cylinder parameterization for mine impact burial prediction," ASME J. Fluids Eng., vol. 127, no. 6, pp. 1515-1520, Nov. 2005.

[50] A. Shlomi, "Underwater optical wireless communication network," SPIE Opt. Eng. J., vol. 49, no. 1, pp. 015001-1-015001-6, 2010.

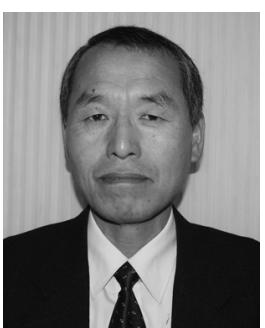

Kwang sub Song (M'81-SM'09) was born in Masan, South Korea. He received the Ph.D. degree from the Department of Electrical and Computer Engineering, Wayne State University, Detroit, MI, with a dissertation titled "A Robust Adaptive Autopilot Design for Decomposed Bank to Turn Missiles."

$\mathrm{He}$ is currently a Visiting Professor with the Department of Oceanography, Naval Postgraduate School, Monterey, CA. His current research interests include artificial-intelligence-based unmanned systems, unmanned underwater mine disposal system design, and integration technology development between heterogeneous unmanned systems.

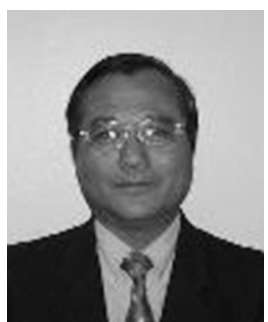

Peter C. Chu received the Ph.D. degree in geophysical fluid dynamics from the University of Chicago, Chicago, IL, in 1985.

$\mathrm{He}$ is currently a Distinguished Professor of oceanography and the Head of the Naval Ocean Analysis and Prediction Laboratory, Department of Oceanography, Naval Postgraduate School, Monterey, CA. His current research interests include naval ocean analysis and prediction, littoral zone oceanography for mine warfare, and unmanned underwater mine disposal system design. 